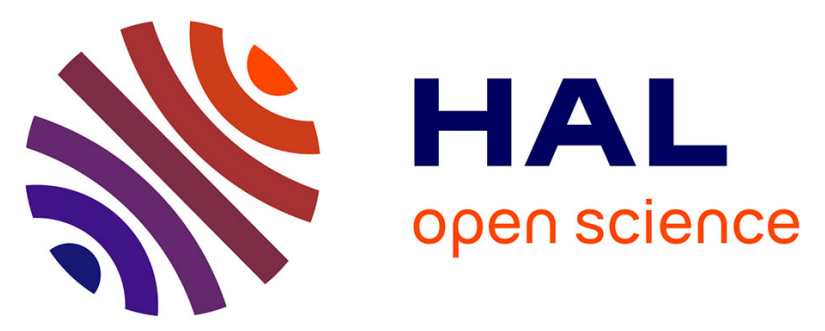

\title{
Note technique. Effet de la température et de l'endosperme sur la dormance et la germination des embryons d'olivier Olea europaea L. variété Picholine marocaine
}

Najiba Brhadda, Dou El Macane Walali Loudyi, Abdelhadi Abousalim, Doha Benali

\section{To cite this version:}

Najiba Brhadda, Dou El Macane Walali Loudyi, Abdelhadi Abousalim, Doha Benali. Note technique. Effet de la température et de l'endosperme sur la dormance et la germination des embryons d'olivier Olea europaea L. variété Picholine marocaine. Agronomie, 2000, 20 (6), pp.643-653. 10.1051/agro:2000156 . hal-00886076

\section{HAL Id: hal-00886076 https://hal.science/hal-00886076}

Submitted on 1 Jan 2000

HAL is a multi-disciplinary open access archive for the deposit and dissemination of scientific research documents, whether they are published or not. The documents may come from teaching and research institutions in France or abroad, or from public or private research centers.
L'archive ouverte pluridisciplinaire HAL, est destinée au dépôt et à la diffusion de documents scientifiques de niveau recherche, publiés ou non, émanant des établissements d'enseignement et de recherche français ou étrangers, des laboratoires publics ou privés. 


\title{
Effet de la température et de l'endosperme sur la dormance et la germination des embryons d'olivier Olea europaea L. variété Picholine marocaine
}

\author{
Najiba BRHADDA ${ }^{\mathrm{a} *}$, Dou El Macane WALALI LOUDYI ${ }^{\mathrm{b}}$, \\ Abdelhadi ABOusAlim ${ }^{\mathrm{b}}$, Doha BenALI ${ }^{\mathrm{a}}$ \\ a Université IBn Tofail, Faculté des Sciences, Département de Biologie, Laboratoire de Physiologie Végétale, Kénitra-Maroc \\ b Institut Agronomique et Vétérinaire Hassan II, Département d'Horticulture, BP 6202, Rabat-Instituts, Maroc
}

(Reçu le 15 novembre 1999 ; révisé le 9 mai 2000 ; accepté le 22 juin 2000)

\begin{abstract}
Effect of temperature and endosperm on the dormancy and germination of olive embryos, Olea europaea L. Moroccan Picholine Variety. The germination capacity of embryos of Moroccan Picholine was higher than seed at $21^{\circ} \mathrm{C}$ ( 69 and $6 \%$ respectively). This inhibitory effect of the endosperm was decreased after a pretreatment at $9^{\circ} \mathrm{C}$ for 21 or 28 days. This effect was not signifiant in the case of embryos excised before chilling of seeds (germination enhanced from 69 to 100\%) compared with embryos chilled while in the intact seed and excised at the end of each chilling period at $9{ }^{\circ} \mathrm{C}$ before transfer at $21^{\circ} \mathrm{C}$ (69 to 96\%). The germination, under constant temperature conditions was optimal at $13{ }^{\circ} \mathrm{C}$, and very low results were obtained at 25 and $29^{\circ} \mathrm{C}$. The pretreatment at $9^{\circ} \mathrm{C}$ has improved the speed of germination, the germination percentage at different temperatures, the elongation of the hypocotyl and suppressed the inhibitory effect of factors causing dormancy at 13 and at $25^{\circ} \mathrm{C}$. Our results show that olive seeds exhibit a dormancy that is caused by factors residing partly in the endosperm and partly within the embryo.
\end{abstract}

olive / Olea europaea L. / germination / dormancy / temperature

Résumé - Les embryons de la Picholine marocaine germent mieux que les graines à $21^{\circ} \mathrm{C}$ ( 69 et $6 \%$ respectivement). Cet effet inhibiteur de l'endosperme est atténué par un prétraitement à $9{ }^{\circ} \mathrm{C}$ pendant 21 ou 28 jours. Cet effet n'est pas significatif dans le cas des embryons excisés avant le prétraitement des graines (germination augmentant de 69 à 100\%) comparés à ceux excisés à partir des graines ayant subi un prétraitement à $9{ }^{\circ} \mathrm{C}$ avant le transfert à $21^{\circ} \mathrm{C}(69$ à $96 \%)$. La germination sous des températures constantes est optimale à $13^{\circ} \mathrm{C}$. Les plus faibles résultats étant obtenus à 25 et à $29^{\circ} \mathrm{C}$. Le prétraitement à $9^{\circ} \mathrm{C}$ améliore le taux et la vitesse de germination aux différentes températures ainsi que l'élongation de l'hypocotyle. Par ailleurs il a annulé l'effet inhibiteur des facteurs provoquant la dormance à 13 et à $25^{\circ} \mathrm{C}$. Nos résultats montrent que les graines manifestent une dormance due à des facteurs résidant en partie dans l'endosperme et en partie dans l'embryon.

olivier / Olea europaea L. / germination / dormance / température

Communiqué par Gérard Guyot (Avignon, France)

Tél. : (212) 777-17-45 ou (212) 7 77-17-58, poste : 1402, fax : (212) 777-58-38. 


\section{Introduction}

Bien que les plants d'olivier soient multipliés commercialement par voie végétative, la multiplication par semis reste toujours importante en fournissant des sujets utiles en tant que porte-greffes et dans le cas des programmes d'amélioration génétique ayant pour objectif la création de nouvelles variétés. Bien que jouissant de conditions de milieu favorables au développement des embryons, les graines d'olivier ne réussissent pas toujours à germer en raison de la double forme de dormance : «mécanique» et «endogène ou physiologique» [1]. Cette dormance est provoquée par des facteurs résidant dans l'endosperme et dans l'embryon luimême $[9,10,12]$. La présence de l'endocarpe (noyau) rend la germination extrêmement difficile. En effet, dans les meilleures conditions, la germination ne commence que très lentement après plusieurs mois, par conséquent son ablation se révèle nécessaire [7].

Parmi les autres facteurs qui jouent un rôle dans le processus de la germination on peut citer, l'époque de maturation et la date de récolte des olives. C'est ainsi que les graines récoltées en septembre germent mieux comparativement aux graines récoltées en novembre ou décembre [7, 10]. La perte du pouvoir germinatif des olives récoltées tardivement pourrait être due à une accumulation plus importante d'huile dans la graine.

La lumière [8] et la température jouent un rôle important dans la germination $[8,12]$. Certains besoins thermiques sont nécessaires pour lever la dormance et réduire le temps nécessaire à la plantule pour devenir autotrophe.

Malgré les progrès réalisés dans le domaine de la germination, tous les problèmes ne sont pas encore résolus entièrement.

Le but de notre étude est de réduire le temps de latence, d'optimiser le pourcentage et la vitesse de germination des embryons de la Picholine marocaine, et d'annuler l'effet inhibiteur des facteurs provoquant la dormance (facteurs résidant dans l'endosperme ou dans l'embryon lui-même) par un prétraitement à $9{ }^{\circ} \mathrm{C}$ suivi de germination à tempé- ratures élevées. Autrement dit, déterminer si la température $9{ }^{\circ} \mathrm{C}$ constitue une température optimale pour la Picholine marocaine comparativement aux autres températures de stratification déjà étudiées par d'autres auteurs chez l'olivier [7].

\section{Matériel et méthodes}

Les graines de la Picholine marocaine fournies par l'INRA de Marrakech, ont été récoltées en octobre 1995 quand la couleur des olives virait du vert jaunâtre au violet. En raison de la sécheresse qui a caractérisé la période 91-95, les fruits produits par des arbres ayant beaucoup souffert du stress hydrique ont un volume réduit par apport à la taille moyenne. Pour séparer les noyaux de la pulpe, les olives sont écrasées entre les doigts une à une. Les noyaux ainsi obtenus et prélevés des olives, deux jours après leur récolte ont été frottés contre du sable, pour parfaire le dépulpage et ont été mis dans une solution de soude à $5 \%$ pendant 20 minutes. Ils ont été ensuite trempés dans une solution d'eau de Javel à $50 \%$ pendant 15 minutes, puis rincés avec de l'eau de robinet. Après ressuyage, les semences ont été conservées à la température ambiante en attendant leur utilisation. L' extraction de la graine se fait par l'application d'une pression contrôlée sur l'endocarpe, à l'aide d'un petit étau à main, ce qui permet de casser les noyaux en laissant intactes les graines [13]. La désinfection des graines précédant leur mise en germination in vitro, a lieu dans l'éthanol à $70 \%$ pendant 2 minutes, puis dans une solution d'hypochlorite de sodium à $50 \%$ additionnée de 2 à 3 gouttes de Tween 20 durant 15 minutes. Après leur rinçage 3 à 4 fois avec de l'eau distillée stérile, les graines ont été soit ensemencées immédiatement, soit mises à imbiber dans de l'eau distillée stérile pendant 24 heures, en vue d'extraire les embryons.

Le milieu de germination utilisé est 1/3MS [11] contenant $30 \mathrm{~g} / \mathrm{l}$ de sucre et solidifié par $7 \mathrm{~g} / \mathrm{l}$ d'agar (bactoagar, Difco). Le pH est ajusté à 5,8 avant l'autoclavage qui a lieu pendant 20 minutes à $120^{\circ} \mathrm{C}$. 
Les embryons ou les graines sont placés individuellement dans des tubes à essai $(21 \times 15 \mathrm{~mm})$ contenant $10 \mathrm{ml}$ de milieu de culture. 10 explants ont été utilisés pour chaque traitement avec 5 répétitions $(n=50)$. Les différentes conditions de température testées sont les suivantes :

$l^{\text {er }}$ essai :

1. Les graines entières sont placées à la température de $9^{\circ} \mathrm{C}$ pendant $0,7,14,21$ et 28 jours, avant leur transfert à la température de $21^{\circ} \mathrm{C}$.

2. Les embryons seuls subissent le même traitement que les graines.

3. Les graines sont incubées à $9{ }^{\circ} \mathrm{C}$ pendant les mêmes périodes que celles indiquées ci-dessus, mais à la fin de chaque période, leurs embryons sont excisés puis transférés à la température de $21^{\circ} \mathrm{C}$.

$2^{e}$ essai :

Les graines et les embryons sont mis directement en culture sans prétraitement sous les températures constantes $9,13,17,21,25$ et $29^{\circ} \mathrm{C}$.

$3^{e}$ essai :

Les graines et les embryons sont incubés à diverses températures $13,17,21,25$ et $29^{\circ} \mathrm{C}$, après avoir subi un prétraitement à $9^{\circ} \mathrm{C}$ pendant 21 jours.

Le suivi de la germination pour les trois essais a lieu pendant 60 jours. L'incubation des explants durant toute la période de culture a lieu sous une photopériode de 16 heures et une intensité lumineuse de $30 \mu \mathrm{E} \cdot \mathrm{m}^{-2} \cdot \mathrm{s}^{-1}$.

On considère qu'un embryon a germé lorsque la pointe de la radicule s'allonge et se courbe vers le bas manifestant son géotropisme positif. Alors que pour la graine, la germination a lieu lorsque la pointe de la radicule perce l'albumen et les enveloppes tégumentaires.

Les observations concernant la germination et l'élongation des hypocotyles sont effectuées régulièrement tous les 4 jours, pendant une période de 60 jours. Les courbes de germination permettent de déterminer le temps de latence et le temps de germination.
Après germination, les plantules sont transplantées dans des pots contenant un mélange de perlite, de sable et de vermiculite $(1 ; 0,5 ; 1)$ et sont placées dans une serre pour l'évaluation de leur développement. Les donnés obtenues ont été soumises à une analyse de la variance à 1 critère (effet de l'endosperme, effet de la durée du prétraitement (Essai 1) ; effet de la température (Essais 2 ou 3 ) et effet du prétraitement à $9{ }^{\circ} \mathrm{C}$ pendant 21 jours (Essai 3) ou à 2 critères (effet de l'interaction de l'endosperme et de la durée du prétraitement à $9{ }^{\circ} \mathrm{C}$ (Essai 1); effet de l'interaction de la température et de l'endosperme (Essais 2 ou 3).

Le test de Newman et Keuls [3] a été utilisé pour classer les valeurs moyennes des facteurs étudiés. Les pourcentages 0 et 100 ont subi, respectivement, la transformation $\left(\frac{1}{4 n}\right)$ et $\left(1-\frac{1}{4 n}\right)$, n étant le nombre d'explants.

Tous les pourcentages ont subi la transformation $\operatorname{Arcsin} \sqrt{\mathrm{P}}$.

\section{Résultats}

\subsection{Essai 1 : effets de l'endosperme et de la durée du prétraitement à $9^{\circ} \mathrm{C}$ sur la germination des embryons et des graines}

\subsubsection{Effet de l'endosperme}

\subsubsection{Durant tout l'essai 1}

La germination est restée faible dans le cas des graines prétraitées à $9^{\circ} \mathrm{C}$, comparées aux embryons excisés au début de l'expérience. Cette différence a été notable pour toutes les durées de prétraitement à $9{ }^{\circ} \mathrm{C}$.

En effet, en l'absence de prétraitement à $9^{\circ} \mathrm{C}$, la germination des embryons a été de $69 \%$ et celle des graines de $6 \%$ confirmant l'effet inhibiteur de l'endosperme. Le taux de germination des embryons a augmenté avec la durée de prétraitement de 7 à 28 jours pour atteindre $100 \%$, alors que les graines n'atteignent leur capacité de 
germination maximale (88\%) qu'après 28 jours à $9^{\circ} \mathrm{C}$ (Fig. 1). Les résultats obtenus confirment ceux obtenus par Walali [13] et Istanbouli [7] qui ont montré que l'endosperme exerce une influence inhibitrice sur l'embryon. Le prétraitement à $9{ }^{\circ} \mathrm{C}$ pendant 21 ou 28 jours a permis d'atténuer l'effet inhibiteur de l'endosperme lors de la germination à $21^{\circ} \mathrm{C}$.

\subsubsection{Pendant le prétraitement à $9^{\circ} \mathrm{C}$}

Le taux de germination augmente de 69 à $100 \%$ pour les embryons excisés au début de l'essai, et de 69 à $96 \%$ pour les embryons excisés à partir des graines ayant subi un prétraitement à $9{ }^{\circ} \mathrm{C}$ avant leur transfert à $21^{\circ} \mathrm{C}$ (Fig. 1). Aucune différence significative n'a été notée entre ces deux types d'explants quelle que soit la durée du prétraitement à $9^{\circ} \mathrm{C}$. Ce résultat montre que l'effet inhibiteur de l'endosperme au cours des phases de prétraitement $9^{\circ} \mathrm{C}$ n'est pas significatif.

\subsubsection{Après le prétraitement à $9{ }^{\circ} \mathrm{C}$}

Dans le cas des embryons excisés à partir des graines ayant déjà subi un prétraitement à $9{ }^{\circ} \mathrm{C}$, le taux de germination augmente significativement après 14 jours de prétraitement à $9{ }^{\circ} \mathrm{C}$ pour atteindre $96 \%$ à 28 jours (Fig. 1). Pour les graines, les taux de germination restent faibles et ne présentent d'amélioration significative que lorsque la durée du prétraitement est de $21(81 \%)$ ou de 28 jours $(88 \%)$. Ceci démontre l'effet inhibiteur de l'endosperme après le prétraitement à $9{ }^{\circ} \mathrm{C}$.

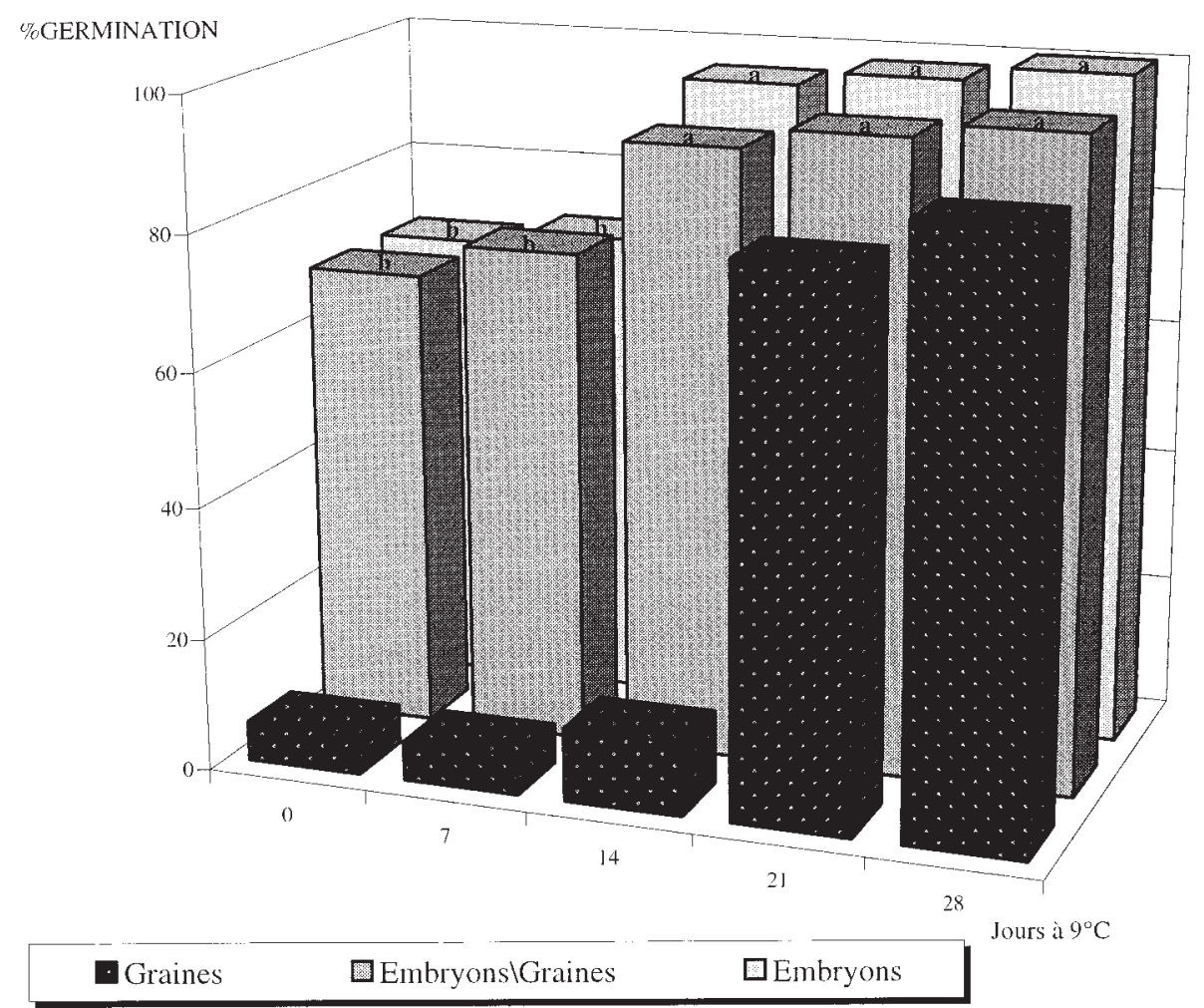

Figure 1. Effet du prétraitement à $9^{\circ} \mathrm{C}$ sur la germination des graines et des embryons après 60 jours de culture. 


\subsubsection{Effet de la durée du prétraitement à $9{ }^{\circ} \mathrm{C}$}

\subsubsection{Cas des graines}

La germination augmente de façon significative après 21 jours de prétraitement à $9^{\circ} \mathrm{C}$. Les taux de germination obtenus après 21 et 28 jours de prétraitement sont respectivement de 81 et $88 \%$.

\subsubsection{Cas des embryons}

Qu'ils soient excisés au début de l'expérience ou à la fin de la période de prétraitement des graines à $9{ }^{\circ} \mathrm{C}$. Leur taux de germination augmente de façon significative à partir de 14 jours de prétraitement. Aucune différence significative n'est observée entre 14, 21 et 28 jours (Fig. 1).

\subsubsection{Effet de l'interaction de l'endosperme et de la durée du prétraitement à $9{ }^{\circ} \mathrm{C}$}

L'analyse de la variance a montré la présence d'une interaction significative entre l'effet de l'endosperme et celui de la durée de prétraitement à $9^{\circ} \mathrm{C}$. Ce sont les embryons excisés et prétraités pendant des durées de 28,21 et 14 jours qui manifestent les niveaux de germination les plus élevés (96 à $100 \%$ ). Le prétraitement à $9^{\circ} \mathrm{C}$ a aussi amélioré l'élongation de l'hypocotyle. Ainsi en l'absence de prétraitement $59 \%$ des embryons développent des hypocotyles de longueur supérieure à $1 \mathrm{~cm}$ après 60 jours de culture et ce pourcentage augmente avec la durée du prétraitement à $9^{\circ} \mathrm{C}$ pour atteindre $90 \%$ pour le premier type d'embryon et $92 \%$ pour le deuxième type (Fig. 2). Après 28 jours de prétraitement à $9^{\circ} \mathrm{C}, 32 \%$ d'embryons excisés au début de l'expérience et $28 \%$ d'embryons excisés après le prétraitement des graines ont manifesté une élongation d'hypocotyle supérieure à $5 \mathrm{~cm}$ après 60 jours de culture (Fig. 3 ). Pour les graines, les hypocotyles dépassant $1 \mathrm{~cm}$ ont été notés dans le cas des prétraitements de 21 jours $(38 \%)$ et de 28 jours (76\%) (Fig. 2). Les hypocotyles ayant une longueur supérieure à $5 \mathrm{~cm}$ ont été observés lorsque le prétraitement à $9{ }^{\circ} \mathrm{C}$
Figure 2. Effet du prétraitement à $9{ }^{\circ} \mathrm{C}$ sur l'élongation de l'hypocotyle $(>1 \mathrm{~cm})$ après 60 jours de culture.
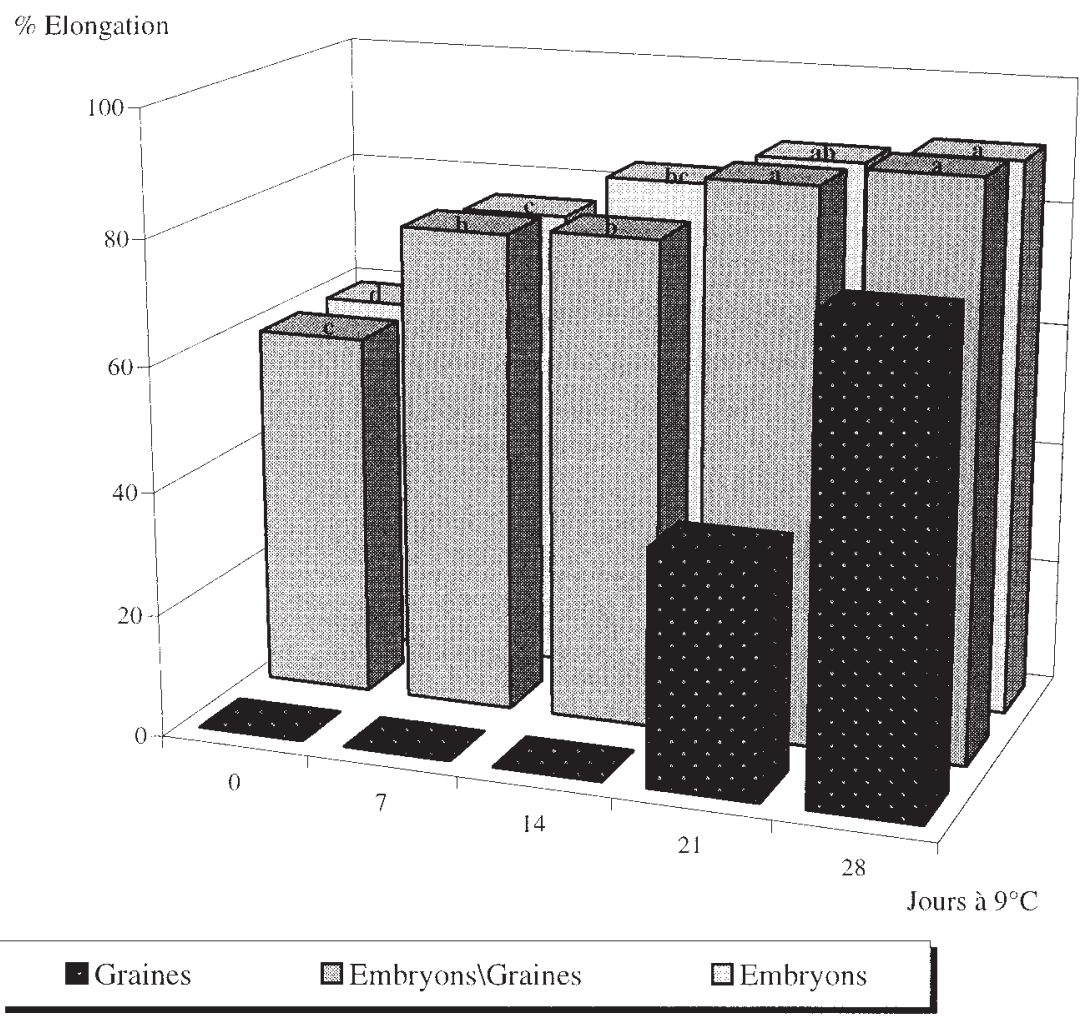
a été de 21 jours (38\%) et 28 jours (60\%) ces deux valeurs étant significativement différentes (Fig. 3).

\subsection{Essai 2 : Effet des températures constantes sur la germination des embryons et des graines}

L'analyse de la variance comparant les températures entre elles à chaque 10 jours montre que le taux de germination le plus élevé, après 60 jours de culture est obtenu à $13{ }^{\circ} \mathrm{C}(95 \%)$ (Fig. 4). L'évolution de la courbe de germination montre l'existence d'un temps de latence de 14 jours, mais ne permet pas de conclure l'existence d'une dormance embryonnaire. A $25^{\circ} \mathrm{C}$ le taux de germination des embryons dormants reste faible (26\%) mais le temps de latence est réduit de moitié (7 jours) par rapport à celui des embryons germant à $13{ }^{\circ} \mathrm{C}$ (Fig. 4). Par ailleurs la température de $13^{\circ} \mathrm{C}$ est considérée comme optimale pour la germination des embryons non dormants $[5,8]$. L'analyse des données ainsi obtenues à $25^{\circ} \mathrm{C}$ en comparaison avec $13{ }^{\circ} \mathrm{C}$ montre que $10 \%$ des embryons ne sont pas dormants, $16 \%$ qui germent difficilement à $25^{\circ} \mathrm{C}$ sont partiellement dormants et le reste, soit $69 \%$ sont totalement dormants.

Pour les températures 17 et $21^{\circ} \mathrm{C}$ le temps de latence est de 6 à 7 jours et le taux de germination de 63-69\%. Un niveau légèrement plus élevé (78\%) est obtenu à $9^{\circ} \mathrm{C}$ bien que le temps de latence ait plus que doublé (18 jours) (Fig. 4). Enfin, les plus faibles résultats sont observés à $29^{\circ} \mathrm{C}$. Ainsi, il apparaît que tous les embryons du lot testé ne sont pas dormants au départ, et que certains d'entre eux ne le sont pas du tout, puisque, ils germent mieux à $25^{\circ} \mathrm{C}$ qu'à $13^{\circ} \mathrm{C}$. Il semble que cette

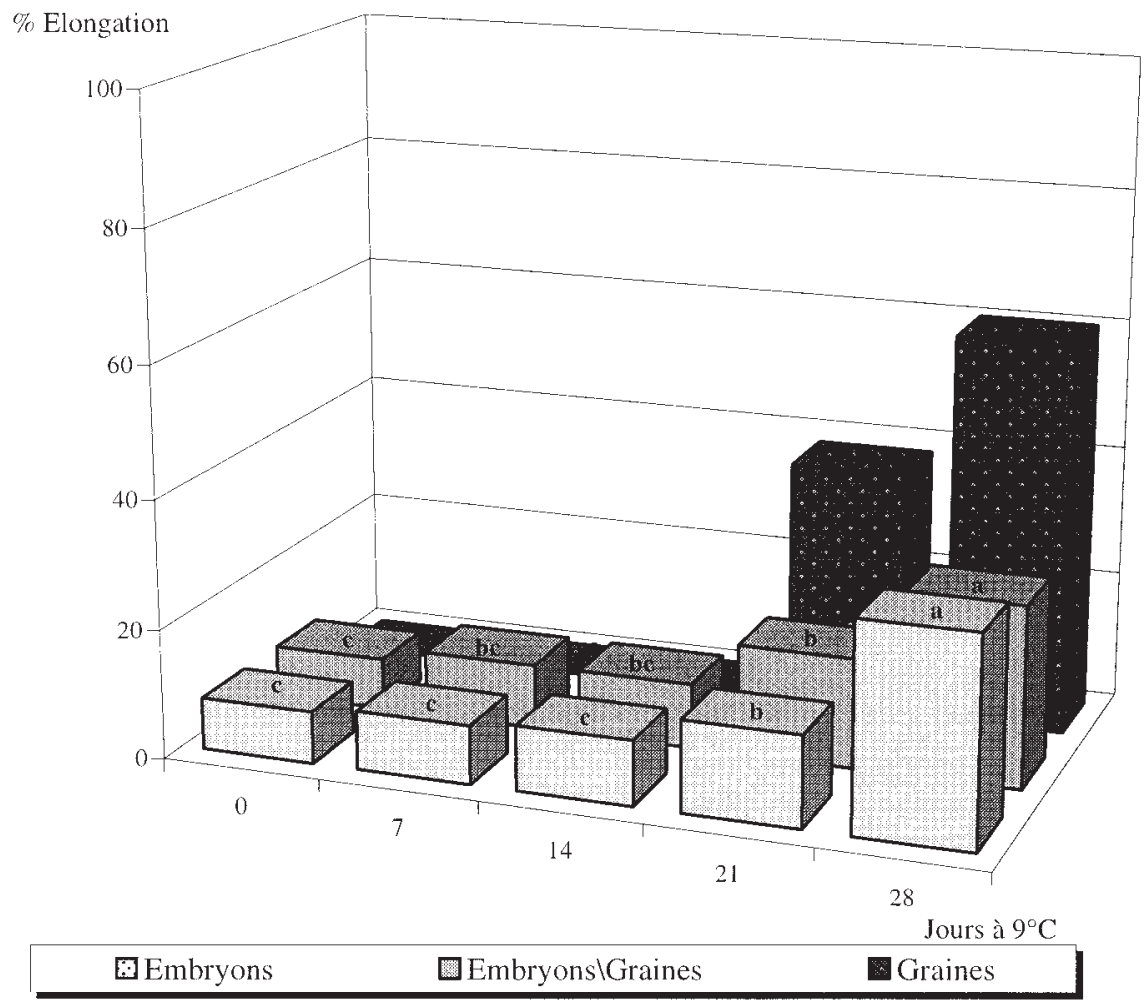

Figure 3. Effet du prétraitement à $9^{\circ} \mathrm{C}$ sur l'élongation de l'hypocotyle $(>5 \mathrm{~cm})$ après 60 jours de culture. 


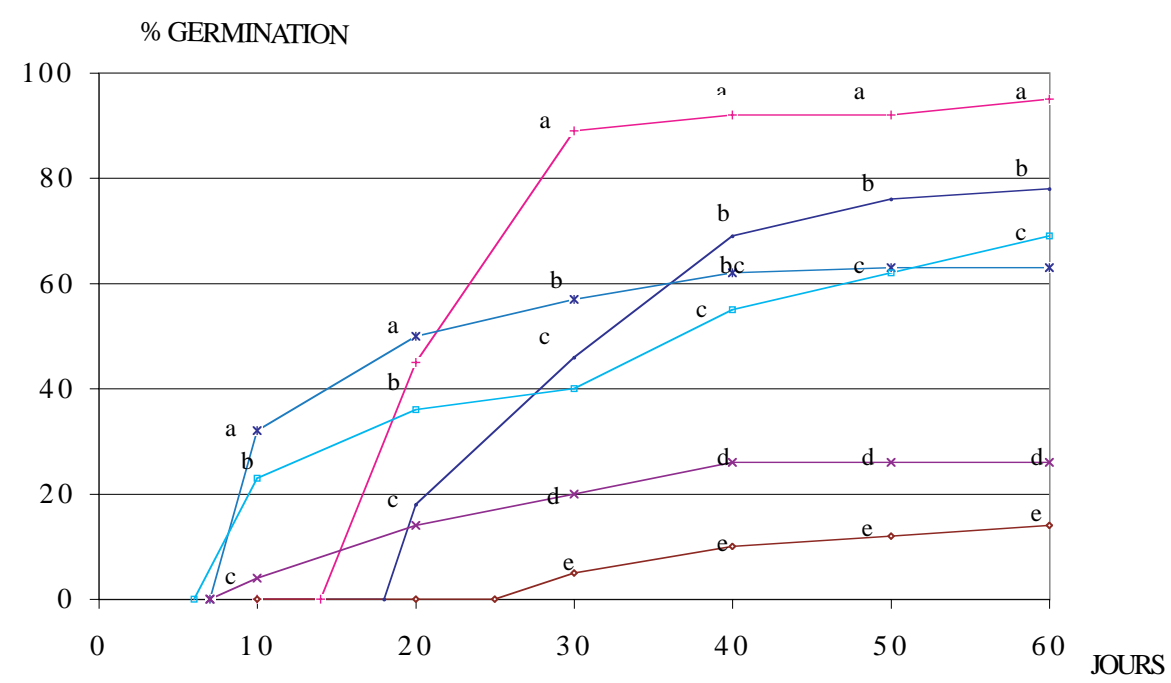

Figure 4. Effet de la température sur la germination des embryons.

dormance embryonnaire ne soit pas un phénomène de tout ou rien [7].

La température optimale de germination des graines reste $13{ }^{\circ} \mathrm{C}(72 \%)$. Des résultats inférieurs $(55$ à $50 \%)$ sont obtenus à 9 et à $17^{\circ} \mathrm{C}$. La germination est très faible à 21 et à $25^{\circ} \mathrm{C}(6$ à $4 \%$ respectivement), et nulle à $29^{\circ} \mathrm{C}$ (Fig. 5).

\subsection{Essai 3 : Effet du prétraitement à $9^{\circ} \mathrm{C}$ pendant 21 jours suivi de la germination à différentes températures}

Si on considère les embryons ayant subi un prétraitement à $9^{\circ} \mathrm{C}$ pendant 21 jours, l'analyse de la variance montre que les résultats sont différents de ceux de l'essai 2, effectués sans prétraitement. En effet, les courbes de germination (Fig. 6) montrent qu'il y a généralement amélioration de la germination. A $13{ }^{\circ} \mathrm{C}$, le temps de latence est réduit de 7 jours et les vitesses et les taux de germination sont les plus élevés. Ainsi, $98 \%$ de germination sont atteints au bout de 30 jours (Fig.6). Comparativement à l'essai 2, la germination des embryons est améliorée au températures 17, 21 et $25^{\circ} \mathrm{C}$. En effet, après 40 jours de culture, le pourcentage de germination passe respectivement de 62 et $55 \%$ à 82 et $84 \%$ pour les températures 17 et $21^{\circ} \mathrm{C}$ et de $26 \%$ à $90 \%$ pour $25^{\circ} \mathrm{C}$ et le résultat final rejoint celui obtenu à $13^{\circ} \mathrm{C}$. De même pour la température $29^{\circ} \mathrm{C}$, on note une amélioration de la germination par rapport à l'essai 2. En effet, le temps de latence est de 18 jours au lieu de 25 jours, et le taux final de $47 \%$ au lieu de $14 \%$. Mais, l'effet de cette température reste significativement le plus faible (Fig. 6). Pour les graines (Fig. 7) on note une amélioration de la germination pour toutes les températures comparativement à l'essai 2. Le meilleur taux de germination $(95 \%)$ s'est manifesté à $13^{\circ} \mathrm{C}$ suivi par celui $(90 \%)$ à $25^{\circ} \mathrm{C}$. A ces deux températures, les taux finaux de germination des embryons et des graines sont similaires. Ainsi, l'effet inhibiteur de l'endosperme est annulé par un prétraitement à $9{ }^{\circ} \mathrm{C}$ pendant 21 jours suivi de la germination à 13 ou $25^{\circ} \mathrm{C}$. La dormance, évidente dans l'essai 2 a complètement disparu dans l'essai 3 après un prétraitement à $9{ }^{\circ} \mathrm{C}$ pendant 21 jours.

\section{Discussion et conclusion}

La réponse des embryons de la Picholine marocaine, aux basses températures indiquent qu'ils sont 


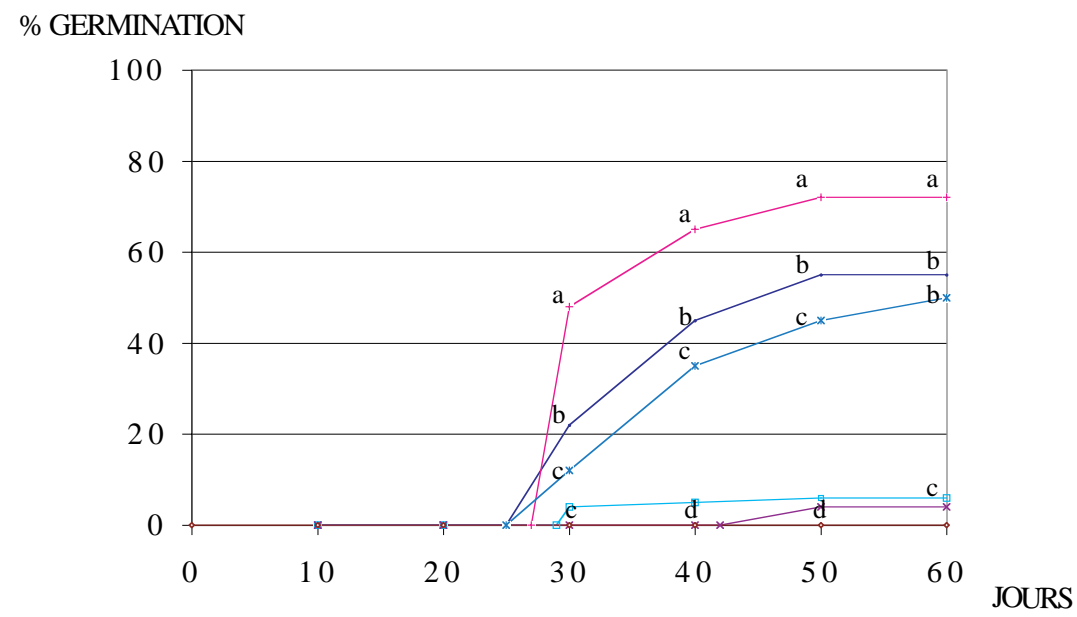

$\because-9-+13-*-17-21 \rightarrow-25 \multimap-29$ TEMPERATURE $^{\circ} \mathrm{C}$

Figure 5. Effet de la température sur la germination des graines.

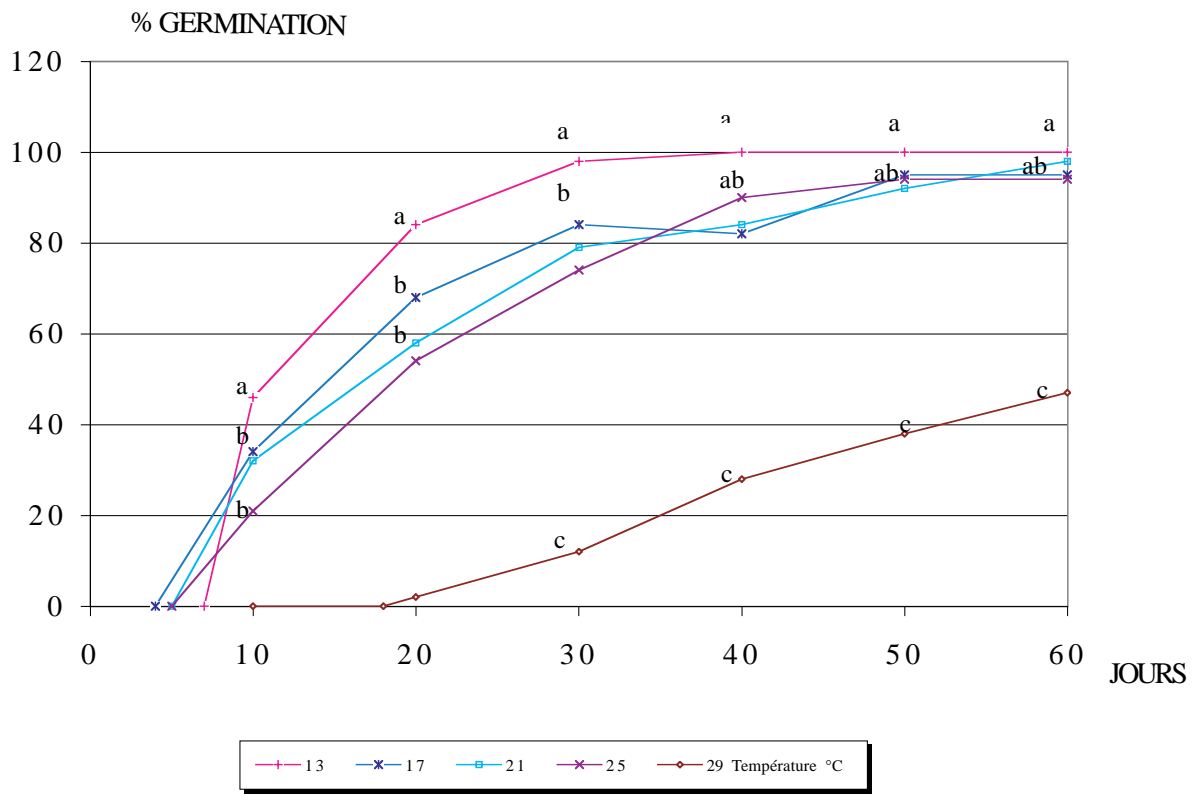

Figure 6. Effet du prétraitement à $9^{\circ} \mathrm{C}$ pendant 21 jours sur la germination des embryons.

en état de dormance. Cette dormance a déjà été observée chez d'autres cultivars d'olivier comme la Picholine de languedoc [7, 9, 13], la variété Oleaster [4] et plus récemment le cultivar chalkidikis [12]. La dormance est due, confirme Lagarda et al. [10] soit à des inhibiteurs (acide abscissique) localisés dans l'endosperme ou dans le tégument séminal, soit à des problèmes nutritionnels (glucides) et physiologiques (niveau d'éthylène endogène, immaturité de l'embryon, etc.). L'endosperme 


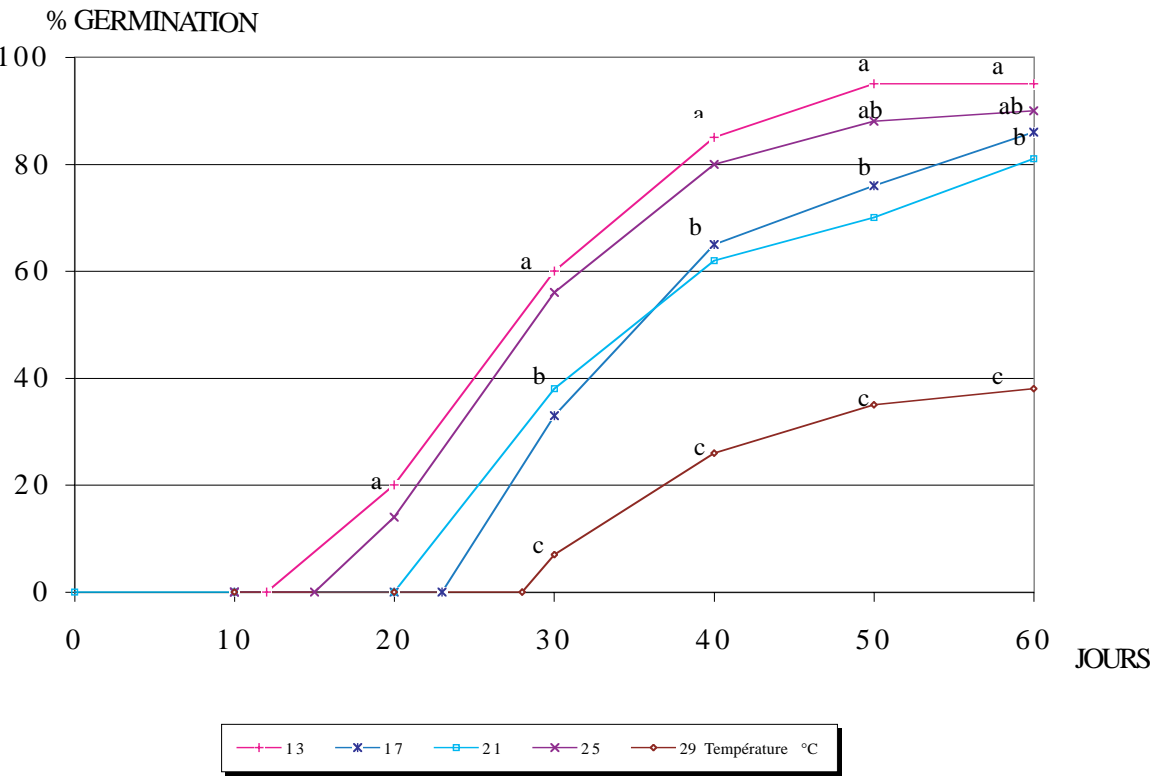

Figure 7. Effet du prétraitement à $9{ }^{\circ} \mathrm{C}$ pendant 21 jours sur la germination des graines.

constitue un obstacle à la germination de l'embryon, soit du fait qu'il libère des substances inhibitrices, soit parce qu'il limite la disponibilité d'oxygène pour l'embryon. Cela coïncide avec les résultats de Istanbouli et Neville [8], Diamantoglou et Mitrakos [4] et ceux de Voyiatzis [12]. L'effet inhibiteur des facteurs diffusés par l'endosperme vers l'embryon est interrompu par un prétraitement à $9^{\circ} \mathrm{C}$ suivi de la germination à température élevée. Cela a permis probablement une désactivation de ces inhibiteurs et confirme les résultats de Voyiatzis [12]. Il est possible de déduire l'importance écologique de l'influence de la succession des différentes températures. En hiver, les températures basses neutralisent le rôle inhibiteur de l'albumen sans permettre la croissance de l'embryon. Plus tard, quand les températures sont plus hautes, l'embryon se développe rapidement à condition d'avoir neutralisé entre-temps, les facteurs inhibiteurs de l'albumen [4].

On a trouvé que les deux types d'embryons soit les embryons excisés avant le prétraitement et ceux excisés après prétraitement à $9^{\circ} \mathrm{C}$ ont une même capacité de germination. Cela n'est pas en accord avec les résultats obtenus par Voyiatzis [12] sur le cultivar Chalkidikis pour lequel le pourcentage de germination des embryons excisés après le prétraitement des graines à $10^{\circ} \mathrm{C}$ est significativement plus élevé. Par ailleurs Istanbouli [7] a trouvé des résultats similaires aux nôtres, mais sur la Picholine de languedoc avec un prétraitement à $4^{\circ} \mathrm{C}$. De même, un prétraitement à $9^{\circ} \mathrm{C}$ a amélioré aussi bien le temps de latence, la vitesse de germination que l'élongation de l'hypocotyle des graines et des embryons. Du Toit et al. [6] ont observé la relation positive entre l'élongation de l'épicotyle et la durée d'un prétraitement au froid pour les graines de Pêcher lorsque aucun prétraitement n'est appliqué (essai 2). La germination est quasiment nulle à 25 et $29^{\circ} \mathrm{C}$. Cette incapacité résulterait, selon Istanbouli [7] en se fondant sur les données de Come [2], d'une réduction de l'intensité respiratoire de l'albumen à cette température supramaximale ou à la présence dans ce tissu de phénol comme c'est le cas chez le pommier qui fixe plus d'oxygène initialement destiné à l'embryon quand la température s'élève. 
L'effet d'un prétraitement à $9{ }^{\circ} \mathrm{C}$ pendant 21 jours a réduit le temps de latence. Ainsi, même aux températures élevées $\left(25\right.$ et $\left.29^{\circ} \mathrm{C}\right)$ la germination de la Picholine marocaine est améliorée, mais ces températures ne sont pas supportées par le cultivar chalkidikis malgré un prétraitement au froid $\left(10^{\circ} \mathrm{C}\right)$ pendant 3 semaines [12]. Les observations de Walali [13] sur le cultivar Sigoise, montrent qu'un prétraitement de 2 semaines à $5^{\circ} \mathrm{C}$ accélère la germination. Par ailleurs Istanbouli [7] a montré sur la Picholine de Longuedoc, que des prétraitements à $4{ }^{\circ} \mathrm{C}$ de courtes durées (ne dépassant pas 2 mois) sont sans effet ou provoquent une légère amélioration de la germination. La comparaison du comportement des autres espèces et des résultats d'Istanbouli [7] relatifs aux basses températures pouvait amener à remettre en question la température de stratification de $4{ }^{\circ} \mathrm{C}$ jusque là considérée comme optimale. Dans nos essais de bons résultats sont obtenus avec un prétraitement à $9^{\circ} \mathrm{C}$ appliqué pendant 21 jours. Les améliorations provoquées par cette température peuvent être interprétées comme une prégermination pour les embryons non dormants, une levée de dormance accompagnée d'une prégermination pour les embryons partiellement dormants et une atténuation de la dormance pour les embryons ou celle-ci est plus intense. De même, le prétraitement à $9^{\circ} \mathrm{C}$ a permis de réduire le temps de latence, d'optimiser le pourcentage et la vitesse de germination, d'annuler l'effet inhibiteur des facteurs provoquant la dormance aux températures optimales de la Picholine marocaine (13 et $25^{\circ} \mathrm{C}$ ) et de l'atténuer aux autres températures. On a remarqué également que la croissance de l'épicotyle et des racines des graines et des embryons à $25^{\circ} \mathrm{C}$ a été nettement supérieure que celle obtenue aux autres températures. De même, la croissance des racines est plus rapide au niveau des plantules provenant des graines que celle des plantules provenant des embryons excisés. Par ailleurs, le développement des plantules issues d'embryons germés in vitro a été plus rapide mais moins vigoureux que celui des plantules issues de graines. Dépourvu de son albumen, tissu nourricier contenant l'essentiel des réserves de la semence, l'embryon nu trouvait beaucoup de difficultés à assurer une bonne croissance aprés repiquage. Les plantules ayant repris, restent, cependant, très minces avec des feuilles plus petites par rapport aux plantules issues de graines. Et toutes les plantules obtenues ont eu, par la suite, une croissance normale dans la serre.

\section{Références}

[1] Cimato A., Propagation et certification des plants. L'élevage des plants d'olivier en pépinière, Actes du séminaire international sur les innovations scientifiques et leur application en oléiculture et oléotechnie, 10-12 mars 1999, Conseil Oléicole International Florence, pp. $1-30$.

[2] Come D., Les obstacles à la germination, Edit. Masson et Cie, Paris, 1970, 162 p.

[3] Dagnelie P., Théorie et méthodes statistique, application agronomique, Gembloux, Presses agronomique, 1980, Vol. 2, p. 463.

[4] Diamantoglou S., Mitrakos K., Sur la culture in vitro de l'embryon d'olivier (Olea europaea L. Var. Oleaster), C. R. Acad. Sci. Série D 288 (1979) 1537-1540.

[5] Douay F., Étude expérimentale de la germination et plus particulièrement de l'activation des semences d'olivier (Olea europaea L.), thèse universitaire d'AixMarseille III, 1980, 167 p.

[6] Du Toit H.J., Jacobs G, Strydom D.K., Role of the various seed parts in peach seedling growth, J. Am. Soc. Hortic. Sci. 104 (1979) 490-492.

[7] Istanbouli A., Étude expérimentale sur la nature des périodes de repos des semences et des bourgeons de l'olivier (Olea europaea L.) mise au point d'une technique de production rapide de jeunes plants, thèse, Université Aix Marseille III, 1976, 135 p.

[8] Istanbouli A., Neville P., Étude de la dormance des semences d'olivier (Olea europaea L.). Mise en évidence d'une dormance embryonnaire, C. R. Acad. Sci. Paris 285 (1977) 41-44.

[9] Istanbouli A., Neville P., Étude de la dormance des semences d'olivier (Olea europaea L.). III. Influence des enveloppes sur la germination, Ann. Sci. Nat. Bot. 13, Ser. 1 (1979) 151-165. 
[10] Lagarda A., Martin G.C, Kester D.E., Influence of environment, seed tissue, and seed maturity on "Manzanillo" olive seed germination, HortScience 18 (1983) 868-869.

[11] Murashige T., Skoog F., A revised medium for rapid growth and bioassays with tobocco tissu culture, Physiol. Plant. 15 (1962) 473-497.
[12] Voyiatzis D.G., Dormancy and germination of olive embryos as affected by temperature, Physiol. Plant. 95 (1995) 444-448.

[13] Walali Loudiyi D.M., Contribution à l'étude de l'action de la température sur la germination des graines d'olivier (Olea europaea L.), DEA, Université de Montpellier Facultés des Sciences, 1971. 